10

\title{
Исследование акустических свойств массива гетерогенных пород и бетонной обделки в натурных условиях
}

\author{
() В.Н. Савельев, Х.Ф. Махмудов
}

Физико-технический институт им. А.Ф. Иофрфе РАН, 194021 Санкт-Петербург, Россия

e-mail: h.machmoudov@mail.ioffe.ru

Поступило в Редакцию 1 марта 2019 г.

В окончательной редакции 29 апреля 2019 г.

Принято к публикации 13 июня 2019 г.

Проведено измерение поля скоростей распространения упругих волн в массиве гетерогенных пород. Осуществлено измерение спектрального состава отклика массива гетерогенных пород и бетонной обделки подземных сооружений на возбуждение его ударом шара, спектр сигнала отклика сконцентрирован в диапазоне 0.7-3.2 kHz. Разработан съемный датчик акустического импульса в комплекте с предварительным усилителем с необходимой амплитудно-частотной характеристикой для установки в скважине диаметром $76 \mathrm{~mm}$ на закладной детали.

Ключевые слова: массив, упругие волны, съемный датчик, акустический процесс.

DOI: $10.21883 /$ JTF.2020.01.48676.74-19

\section{Введение}

Нагрузка переводит тело в метастабильное состояние, и трещинообразование является формой релаксации (ее „жесткой моды“, лимитирующей процесс при исчерпании более „мягкой моды“ - пластической деформации). При зарождении и росте трещин происходит сброс упругой энергии, что и обусловливает причину их возникновения. Образование трещины размером $r$ в среде под напряжением $\sigma$ приводит к энерговыделению [1]

$$
u \approx \frac{\sigma^{2} r^{3}}{E}
$$

где $E$ - модуль упругости.

Сравним энерговыделение на двух стадиях трещинообразования. Зарождению начальных трещин отвечает выделение энергии (отражающее уровень напряжений, размер трещин и упругость материала). На первой стадии эта величина примерно одинакова. На второй стадии в очаге разрушения действуют повышенные напряжения $\sigma_{c} \geq \sigma$, что при генерации новых трещин приводит к энерговыделению $u_{c}>u$, причем величина $u_{c} / u$ непрерывно растет. Таким образом, в твердом теле импульсный источник однократного механического воздействия порождает сложный акустический процесс, представляющий собой процесс распространения объемных продольной $P$ и сдвиговой $S$ волн, которые, в свою очередь, на границах порождают вторичный процесс собственных колебаний образца. Регистрация энерговыделения [1] (его изменения) позволяет фиксировать смену стадий и обнаружить переход к предразрывному состоянию, а линейная экстраполяция измеренной зависимости $u_{c} / u$ к нулю времени дает нижнюю оценку остаточного ресурса долговечности $\Delta \tau$.
При оценке устойчивости подземных сооружений основной задачей является определение нагрузок [17], действующих на конструктивные элементы горных выработок, в целях оценки их несущей способности при воздействии определенных усилий техногенного и природного характера [8-11]. Нагрузки на конструктивные элементы обусловлены влиянием таких геологических и геомеханических факторов [12-14], как глубина заложения горных выработок, естественное напряженное состояние массива пород $[15,16]$, геометрические размеры камер и целиков (тупиковый подземный цех), состав и физикомеханические свойства пород, структурное строение массива [17].

В процессе натурных экспериментов исследованы акустические свойства бетонной обделки и массива гетерогенных пород подземных сооружений ФГУП „ГХК“ („Горно-химический комбинат“ „Росатом“ Россия, г. Железногорск, Красноярский край), в районе скважины № 5. Испытан разработанный нами датчик регистрации импульсов акустической эмиссии (АЭ) для установки в скважинах диаметром $76 \mathrm{~mm}$. По результатам этих экспериментов от организации ФГУП „ГХК“ „Росатом“ получен акт (№ 212-25-60-01/2379 от 15.05.2018 г.) о внедрении (использовании) результатов работы Х.Ф. Махмудова. Выявлены акустические характеристики горных выработок в наиболее типичных узлах [18], а также рассмотрена модель и математический аппарат для оценки и слежения за развитием процессов проявления горного давления в подземных сооружениях [19]. Установлена возможность обнаружения момента начала формирования очага разрушения в подземных сооружениях [20]. 


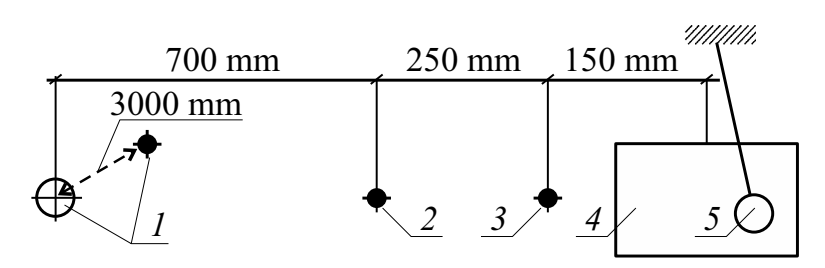

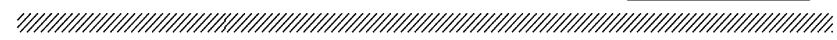

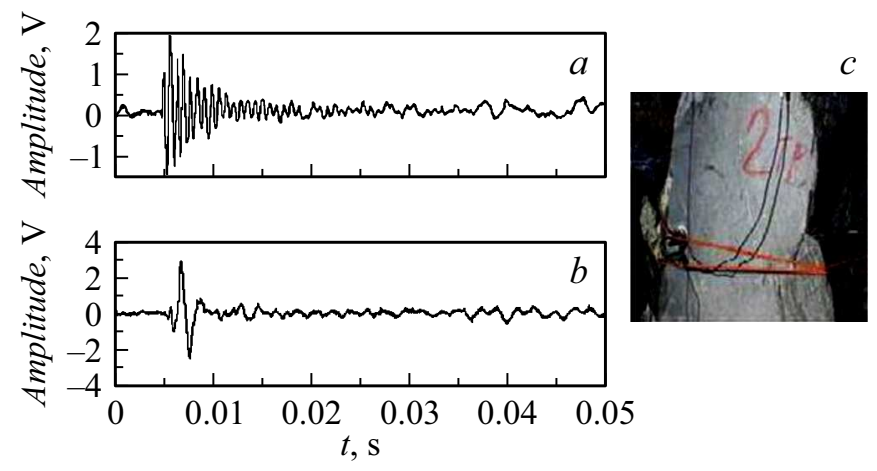

Рис. 1. Измерение акустических свойств бетонной обделки и горного массива в районе скважины СГС-5. 1 - скважина, в которой размещен шахтный датчик на глубине $3 \mathrm{~m}, 2-$ пьезопленочный датчик, 3 - запускающий датчик, 4 - места удара (стальная пластина или закладная), 5 - массивный стальной шар; $a$ - примеры сигналов, зарегистрированных пьезопленочным датчиком, $b-$ шахтным датчиком, $c-$ фото крепежа контрольного датчика.

\section{Выбор частотного диапазона регистрации АЭ и прозвучивание гетерогенного породного массива объекта контроля}

Проведено предварительное измерение поля скоростей распространения упругой волны в породе в районе установки датчика в выбранной скважине (рис. 1). Скорость распространения упругой волны составила величину $5318 \mathrm{~m} / \mathrm{s}$, что удовлетворительно согласуется с расчетной скоростью $(5505 \mathrm{~m} / \mathrm{s})$.

Для измерения энергии источника акустического импульса (АИ) в абсолютной шкале единиц (J) по регистрируемым АИ в лабораторных условиях был проведен анализ энергетического баланса „источник АИ“-,,передающая среда“-,приемник АИ“ с применением аппарата спектрального анализа. В эксперименте измерялась доля механической энергии, затраченной на возбуждение упругой волны, и независимо измерялось напряжение в упругой волне, по которому рассчитывалась энергия волны. Источником излучения волны служило упругое соударение стального шара (источник АИ) с поверхностью стеклянного куба (передающая среда). Напряжения в упругой волне измерялись методом фотоупругости (приемник АИ). Работоспособность такого способа определения энергии источника упругих волн защищена патентом 5056107 РФ [20].
Сопоставление двух независимых методов [1] определения энергии упругого взаимодействия дало расхождение результатов менее чем на $20 \%$. То есть для модельного случая практически вся энергия упругого соударения перешла в энергию упругих колебаний куба, который, в свою очередь, обладает практически идеальной передаточной функцией. Был определен также спектральный состав энергии взаимодействия. При этом нужно отметить, что эти результаты позволяют определять как параметры источника сигнала, так и структуру передающейся с трансформацией сигнала среды. Для адаптации этой методики на подземных сооружениях ФГУП „ГХК““ был разработан, изготовлен и калиброван для измерения напряжений упругой волны пьезопленочный приемник акустического импульса (ППАИ) с линейной амплитудно-частотной характеристикой в диапазоне до $20 \mathrm{kHz}$ [19]. Также разработан и изготовлен съемный датчик акустической эмиссии в комплекте с предварительным усилителем для установки в скважине диаметром $76 \mathrm{~mm}$ на закладной детали [19]. ППАИ был установлен в подземных сооружениях ФГУП „ГХК“ в районе скважины (рис. 1, 1). Им было проведено измерение спектрального состава отклика массива горных пород на возбуждение его ударом шара массой $M=4.684 \mathrm{~kg}$ (рис. 1,5), а также проведена оценка энергии в упругой волне, формируемой от удара шаром. Сопоставление оценки величины упругой энергии (около $0.3 \mathrm{~J}$ ) с потерей механической энергии при ударе шаром (около $6 \mathrm{~J}$ ) носит, весьма приближенный характер. Это связано, во-первых, с тем, что при возбуждении упругой волны путем удара шаром по поверхности выработки соударение не является чисто упругим (рис. 2), оно сопровождается разрушением породы в месте контакта, на что и идет значительная доля потерянной при соударении механической энергии шара, во-вторых, с тем, что не известна передаточная
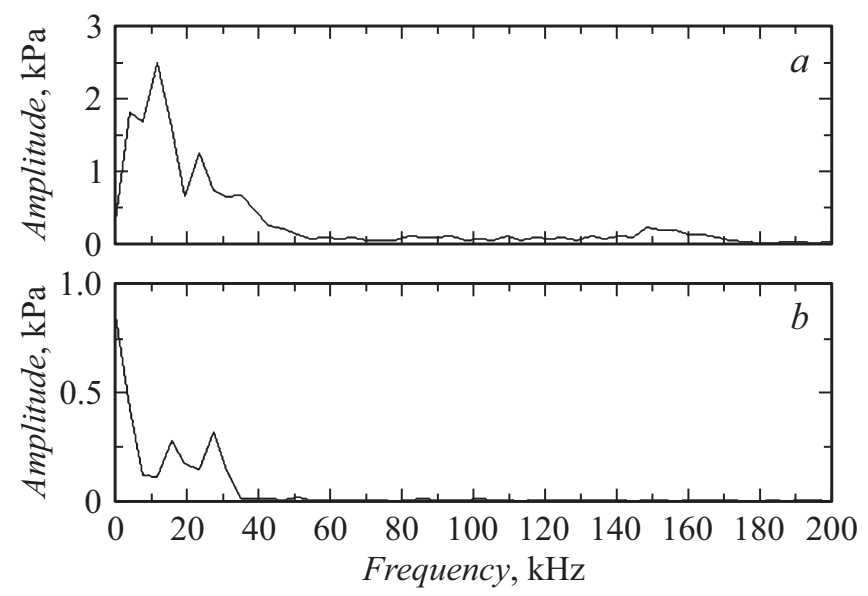

Рис. 2. $a-$ спектр сигнала, зарегистрированного в месте действия динамического излучателя с наименьшей энергией; $b$ - спектр сигнала, зарегистрированного в месте приема на расстоянии $870 \mathrm{~mm}$ от места удара до шахтного датчика рис. $1,1,4$. 
функция среды, которая может быть определена после исключения первой причины расхождения результатов. Поэтому более корректная оценка энергии производилась путем возбуждения акустического импульса ударом шара по закладной стальной детали (или стальной пластине) (рис. 1,4). Определенная таким способом спектральная плотность возбуждения массива горных пород от удара шаром концентрируется в диапазоне $0.7-3.2 \mathrm{kHz}$ (рис. 2).

\section{Акустические свойства бетонной обделки в подземных сооружениях}

Проанализирована возможность метода акустической эмиссии для регистрации трещинообразования и разрушения гетерогенных пород. Измерение скорости упругих волн в бетонном слое толщиной $h=1500 \mathrm{~mm}$ производились на базе $980 \mathrm{~mm}$. Регистрация моментов времени прихода волны производилась по первому вступлению сигналов (рис. 3). Согласно данным измерениям, скорость в слое бетона равна $3920 \mathrm{~m} / \mathrm{s}$. Была произведена также оценка скорости волн в бетоне с помощью расчета модуля упругости $E_{\text {eff }}$ для плоской волны по модулю Юнга (для бетона он равен $36.1 \mathrm{kPa}$ ) и коэффициенту Пуассона $(0.22)$. В результате получили скорость плоской продольной $c_{L}$ волны в виде:

$$
c_{L}=\sqrt{E_{\mathrm{eff}} / \rho}
$$

где $\rho$ - плотность бетона $\left(2200 \mathrm{~kg} / \mathrm{m}^{3}\right)$. Тогда получаем скорость плоской продольной волны в бетоне $c_{L}=4343 \mathrm{~m} / \mathrm{s}$. Скорость вдоль слоя оказывается меньше скорости плоских волн $c_{L}$. Для определения типа волны, скорость которой соответствует измеренной $(3920 \mathrm{~m} / \mathrm{s})$, необходимо рассчитать дисперсионные кривые для бетонного слоя $h=1500 \mathrm{~mm}$. Для этого необходимо дополнительно получить скорость сдвиговых волн для
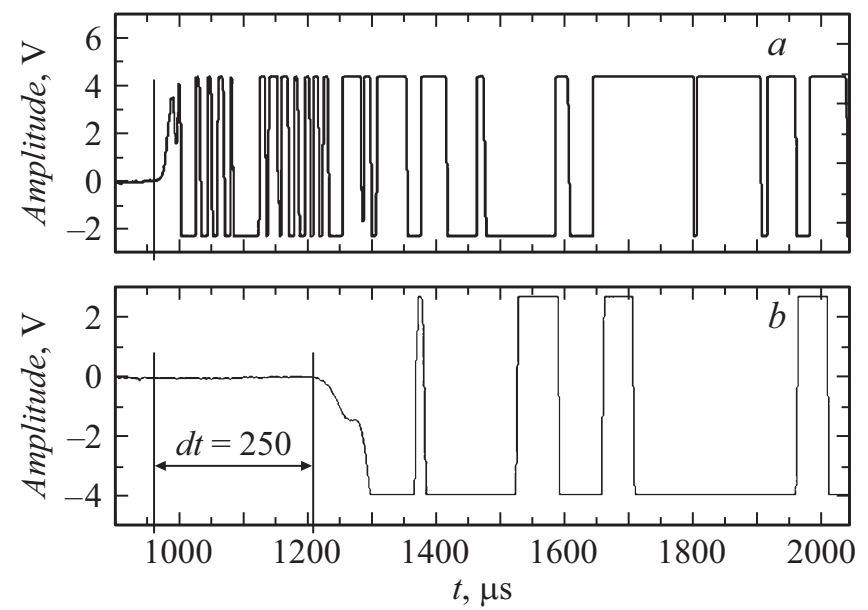

Рис. 3. Измерение скоростей упругих волн в бетонном слое: $a$ - запускающий датчик, $b$ - датчик на расстоянии $980 \mathrm{~mm}$; $d t-$ время прохождения упругих волн в бетонном слое от запускающего датчика до регистрирущего.
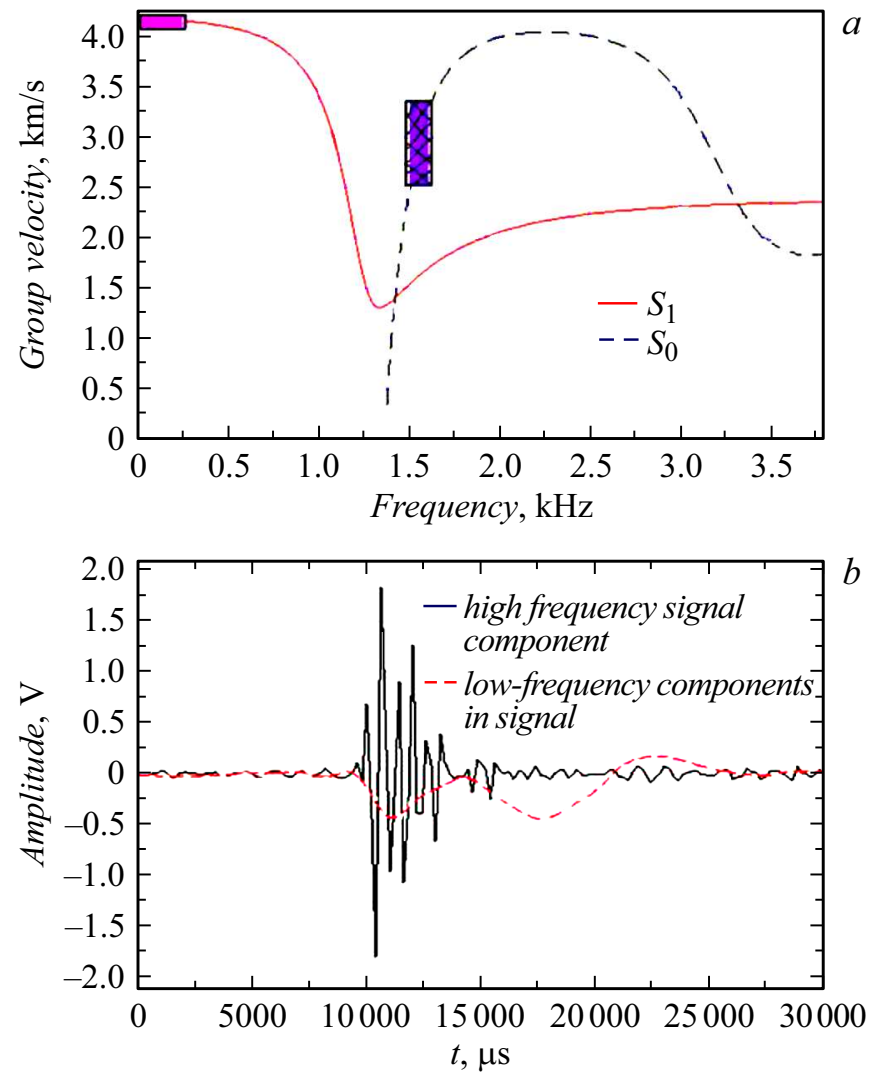

Рис. 4. Дисперсионные кривые для симметричной Лэмбовской моды $S_{1}$ (штриховая линия), и для симметричной нулевой моды $S_{0}$ (сплошная линия), рассчитанные для бетонной обделки толщиной $1500 \mathrm{~mm}(a)$, представление этих двух мод на амплитудно-временной плоскости $(b)$.

бетона. Модуль сдвига $\mu$ для бетона определялся через модуль Юнга $E$ и коэффициент Пуассона $v$, как $E=2 \mu(1+v)$, отсюда $\mu=E / 2(1+v)=14.8 \mathrm{kPa}$. Модуль упругости и коэффициент Пуассона брались из данных о физико-механических свойствах горных пород лаборатории физических проблем разработки пластовых месторождений Горного института им. Плеханова. Скорость сдвиговой $c_{T}$ волны в бетоне получим по формуле:

$$
c_{T}=\sqrt{\mu / \rho}
$$

и в итоге $c_{T}=2594 \mathrm{~m} / \mathrm{s}$.

На рис. 4, a показаны дисперсионные кривые для симметричной Лэмбовской моды $S_{1}$ (штриховая линия) $[21,22]$, и для симметричной нулевой моды $S_{0}$ (сплошная линия). Видно, что зарегистрированная высокочастотная составляющая спектра сигнала находится в диапазоне $1.25-1.75 \mathrm{kHz}$. Физически эта волна представлена симметричными относительно средней линии бетонного слоя колебаниями сжатия-растяжения. Приближенно частота $f_{n}$ этой волны связана с мощностью слоя формулой стоячей волны

$$
f_{n}=\frac{2 n-1}{2 h} c_{L}, \quad \text { где } n=1
$$


Подставляя значения $c_{L}$ и $h$, получаем значение $f_{n}$, равное $1.45 \mathrm{kHz}$, что приближенно соответствует доминантной частоте высокочастотной составляющей сигнала $(1.6 \mathrm{kHz})$ (рис. 4). Из рис. 4, $a$ видно, что скорости распространения такой волны лежат в области $3000 \mathrm{~m} / \mathrm{s}$ (заштрихованный прямоугольник).

Зарегистрированная низкочастотная составляющая спектра сигнала $(0-0.25 \mathrm{kHz})$ соответствует нулевой моде $S_{0}$, скорость распространения которой приближенно равна $4000 \mathrm{~m} / \mathrm{s}$ (незаштрихованный прямоугольник). Отсюда можно заключить, что регистрируемое первое вступление при измерении скорости распространения сигнала вдоль слоя бетона соответствует моменту прихода нулевой моды $S_{0}$. На рис. $4, b$ показана отфильтрованная высокочастотная составляющая (сплошная линя), и низкочастотная составляющая (штриховая линя).

Таким образом, из рассмотренных случаев возбуждения можно заключить, что в случае действия источника упругих волн непосредственно в бетонной обделке горной выработки энергия ударного воздействия на горный массив преобразуется в распространяющиеся нормальные волны $S_{0}$ и $S_{1}$, обусловленные упругими свойствами бетона и толщиной обделки. Регистрируемое первое вступление при измерении скорости распространения сигнала вдоль слоя бетона соответствует моменту прихода нулевой моды $S_{0}$, скорость в слое бетона которой равна $3920 \mathrm{~m} / \mathrm{s}$.

\section{Акустические свойства гетерогенного массива}

Измерение скоростей упругих волн в массиве горных пород производились на базе $5121 \mathrm{~mm}$ (рис. 5). Также было проведено измерение спектрального состава отклика массива горных пород на возбуждение его ударом шара массой $M=4.684 \mathrm{~kg}$ по закладной стальной детали (или стальной пластине) (рис. 5, 4). Регистрация моментов времени прихода волны производилась по первому вступлению сигналов. Результаты измерения скоростей упругих волн в массиве горных пород приведены на

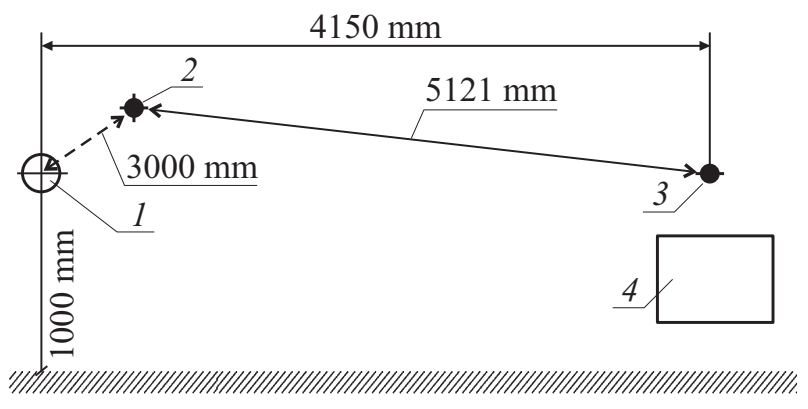

Pис. 5. Схема измерения скоростей упругих волн в массиве горных пород. 1 - скважина (целик), в которой размещен шахтный датчик на глубине $3000 \mathrm{~mm}, 2$ - шахтный датчик на глубине $3000 \mathrm{~mm}, 3$ - запускающий датчик, 4 - место удара (стальная пластина).

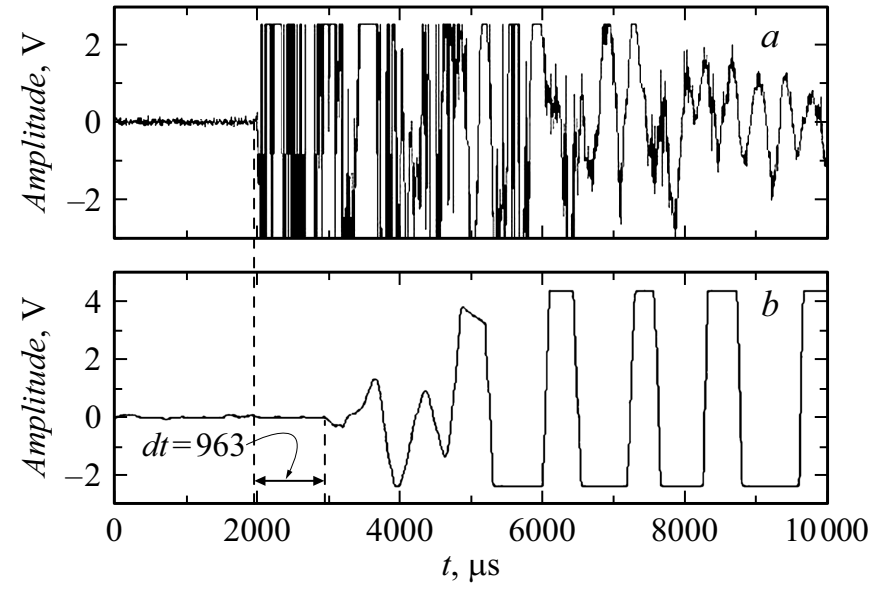

Рис. 6. Измерение скоростей упругих волн в массиве горных пород: $a-$ запускающий датчик, $b-$ регистрирующий датчик на расстоянии $5121 \mathrm{~mm}$; $d t$ - время прохождения упругих волн в массиве горных пород от запускающего датчика до регистрирущего.

рис. 6. Измеренная скорость упругих волн в массиве горных пород оказалась равной $5318 \mathrm{~m} / \mathrm{s}$. Для проверки соответствия данного значения скорости упругим константам гнейсов, слагающих массив горных пород, оценим скорость приближенно описанным выше способом по формуле (1), где $\rho-$ плотность пород горного массива, равная $2700 \mathrm{~kg} / \mathrm{m}^{3}, E-$ модуль Юнга (для гнейсов он равен 60-80 kPa), $v$ - коэффициент Пуассона (для гнейсов он равен $0.23-0.24)$. Расчетное значение модуля упругости $E_{\text {eff }}$ для гнейсов равно $82 \mathrm{GPa}$. Оценочное значение скорости оказывается равным $5505 \mathrm{~m} / \mathrm{s}$, что соответствует приблизительно измеренной скорости.

\section{Обсуждение результатов}

Для корректного применения метода АЭ при регистрации трещинообразования в гетерогенном массиве необходимо знать размеры и геометрию подземных сооружений, особенности приграничных зон при разрушении, физико-механические свойства пород [23-35], особенности динамического поведения амплитуд сигналов акустической эмиссии, включая параметры блочной структуры и поле скоростей распространения звука, наличие и месторасположение тектонических нарушений [36-41]. Как показывает опыт, первоначально поставленные задачи со временем модифицируются, возникают новые [42-45], например, как от локального контроля без определения координат источников АЭ отдельных ответственных или механически неустойчивых элементов объекта [46-50] перейти в дальнейшем к его полному контролю с определением координат источников с энергией выше заданной. Очень важен выбор частотного диапазона регистрации импульсов АЭ, поскольку от частотного диапазона с одной стороны, 
Зависимость верхней границы (f+) частотного диапазона регистрации сигналов АЭ от линейного размера зоны контроля

\begin{tabular}{c|c}
\hline $\begin{array}{c}\text { Линейный размер } \\
\text { зоны управления } \\
(L, \mathrm{~m})\end{array}$ & $\begin{array}{c}\text { Верхняя граница } \\
\text { частотного диапазона } \\
\left(f^{+}, \mathrm{Hz}\right)\end{array}$ \\
\hline 1000 & 100 \\
100 & 500 \\
10 & 3000
\end{tabular}

согласно таблице, зависит энергетический диапазон разрушения, подлежащего контролю, а с другой стороны, учитывая сильную зависимость коэффициента затухания акустического импульса от частоты, необходимо соответствие характеристик антенны датчиков акустического импульса размерам объекта контроля [51-53].

\section{Выводы}

Анализ частотного состава АЭ на различных стадиях трещинообразования важен для изучения физики явления потери прочности при разрушении, поскольку:

- в неповрежденных гетерогенных породах на микроуровне акустические волны излучаются в процессе трещинообразования в зернах гетерогенных пород $(0.5-2.00 \mathrm{MHz})$, когда преодолен локальный предел прочности материала;

- в гетерогенных породах с поверхностью ослабленного механического контакта, чем является, например, существующий разлом, акустические волны излучаются при сдвиге вдоль разлома $(0.01-10 \mathrm{kHz})$, который начинает распространяться, как только преодолено трение на поверхности.

\section{Благодарности}

Авторы выражают благодарность Томилину Н.Г., Савельеву Д.В., Медведеву В.Н., Круглову С.Ю., Розанову А.О. за плодотворное обсуждение результатов.

\section{Конфликт интересов}

Авторы заявляют, что у них нет конфликта интересов.

\section{Список литературы}

[1] Пат. РФ № 2037821, 1995. Петров В.А., Пикулин В.А., Розанов А.О., Савельев В.Н., Станчии, С.А. Способ определения энергии сигнала акустической эмиссии в твердом теле.

[2] Томилин Н.Г., Дамаскинская Е.Е., Павлов П.И. // Физика земли. 2005. № 8. С. 69-78.

[3] Козырев А.А., Журавлева О.Г., Федотова Ю.В. // Фундаментальные и прикладные вопросы горных наук. 2015. № 2. C. $108-113$.
[4] Куксенко В.С., Махмудов Х.Ф. // Геология и геофизика. 2017. T. 58. № 6. C. 915-923.

[5] Менжулин М.Г., Махмудов Х.Ф., Щербаков И.П. LAMBERT Academic Publishing, 2014. $68 \mathrm{c}$.

[6] Lockner D.A., Stanchits S.A. // J. Geophys. Research B: Solid Earth. 2002. Vol. 107. N 12. P.ETG 13-1-13-14.

[7] Stanchits S.A., Lockner D.A., Ponomarev A.V. Bulletin of the Seismological Society of America. 2003. Vol. 93. N 4. P. 1803-1822.

[8] Куксенко В.С., Мирошниченко М.И., Савельев В.Н., Султонов У. Сб. Экспериментальная сейсмология. М.: Наука, 1983. C. 2667.

[9] Махмудов Х.Ф., Менжулин М.Г., Захарян М.В., Султонов У., Абдурахмонов 3.М. // ЖТФ. 2015. Т. 85. Вып. 11. C. $79-85$.

[10] Куксенко В.С., Махмудов Х.Ф., Манжсиков Б.Ц. // Физикотехнические проблемы разработки полезных ископаемых. 2010. № 4. С. 29-40.

[11] Завьялов А.Д. // ФТТ. 2005. Т. 47. Вып. 6. С. 1000-1008.

[12] Кочарян Г.Г., Марков В.К., Марков Д.В., Перник Л.М. // Физическая мезомеханика. 2011. Т. 14. № 6. С. 63-70.

[13] Мельников Н.Н., Козырев А.А., Панин В.И. // Геоэкология, инженерная геология, гидрогеология, геокриология. 2015. № 5. C. 425-433.

[14] Adushkin V.V., Oparin V.N. // J. Mining Sci. 2014. Vol. 48. N 2. P. 203-222.

[15] Смирнов В.Б., Панамарев А.В., Завьялов А.Д. // Физика земли. 1995. № 1. С. 38-58.

[16] Томилин Н.Г., Воинов К.А., Селивоник В.Г., Глотов С.В. Тез. докл. VIII Междунар. школы-семинара „Физические основы прогнозирования разрушения горных пород“. 2010. СПб. С. $86-87$.

[17] Мансуров В.А., Рустамова М.3., Султонов У., Куксенко В.С., Махмудов Х.Ф. // Физико-технические проблемы разработки полезных ископаемых. 2009. № 4. С. 55-59.

[18] Мельников Н.Н., Козырев А.А. // Горный информационноаналитический бюллетень (Научно-технический журнал). Спец. выпуск. 2015. № 56. С. 7-23.

[19] Махмудов Х.Ф., Савельев В.Н., Савельев Д.В., Медведев В.Н., Круглов С.Ю. В кн. (сборнике): XXIII Петербургские чтения по проблемам прочности, посвященные 100-летию ФТИ им. А.Ф. Иоффе и 100-летию со дня рождения чл.-корр. АН СССР А.В. Степанова. 2018. СПб. C. $136-137$.

[20] Савельев В.Н., Розанов А.О., Савельев Д.В., Медведев В.Н., Круглов С.Ю., Махмудов Х.Ф. В сб. VII Междунар. конф. „Деформация и разрушение материалов и наноматериалов“. 2017. М. С. 672-673.

[21] Розанов А.О. Куксенко В.С., Савельев В.Н., Станчии С.А., Пикулин В.А. // Письма в ЖТФ. 1993. Т. 19. Вып. 4. C. 28-32.

[22] Лексовский А.М., Боровиков В.А., Бозоров Н.С., Абдуманонов А., Синани А.Б., Пилецки С.А. // Письма в ЖТФ. 2002. Т. 28. Вып. 16. С. 90-94.

[23] Rozanov A.O., Savel'ev V.N., Stanchits S.A. Proceed. of the EAGE 57th Conf. Technical Exhibition, Glasgow, Scotland, B0004. 1995.

[24] Rzayev A.G., Rasulov S.R. News of the Ural State Mining University 3. 2018. C. 89-97. 
[25] Aliev T.M., Rzaev A.G., Rasulov S.R., Guluev G.A. Vestnik Azerbaydzhanskoy inzhenernoy akademii [Bulletin of the Azerbaijan Engineering Academy]. 2016. Vol. 8. N 3. P. 98-101.

[26] Закалинский В.М., Кочанов А.Н., Красюкова Е.В. В кн.: Проблемы и перспективы комплексного освоения и сохранения земных недр. 2018. С. 96-99.

[27] Зайщев Д.В., Кочанов А.Н., Пантелеев И.А., Панфилов П.Е. // Известия РАН. Серия физическая. 2017. Т. 81. № 3. C. 366-369.

[28] Гульельми А.В., Зотов О.Д., Завьялов А.Д. // Физика Земли. 2014. N 1. С. 66.

[29] Викулин А.В., Махмудов Х.Ф., Иванчин А.Г., Герус А.И., Долгая А.А. // ФТТ. 2016. Т. 58. Вып. 3. С. 547-557.

[30] Викторов С.Д., Кочанов А.Н. // Физико-технические проблемы разработки полезных ископаемых. 2016. № 5. C. $76-83$.

[31] Panthi A., Singh H.N., Shanker D. // Geosciences. 2013. Vol. 3. P. 5.

[32] Щербаков И.П., Веттегрень В.И., Мамалимов Р.И., Махмудов Х.Ф. // ФТТ. 2017. Т. 59. Вып. 3. С. 556-558. [Shcherbakov I.P., Vettegren V.I., Mamalimov R.I., Makhmudov Kh.F. // Phys. Solid State. 2017. Vol. 59. N 3. P. 575-577.] DOI: $10.1134 / \mathrm{S} 1063783417030295$

[33] Щербаков И.П., Веттегрень В.И., Мамалимов Р.И., Махмудов Х.Ф. // ЖТФ. 2017. Т. 87. Вып. 8. С. 1182-1184. [Shcherbakov I.P., Vettegren V.I., Mamalimov R.I., Makhmudov Kh.F. // Tech. Phys. 2017. Vol. 62. N 8. P. 1194-1196.] DOI: $10.1134 / \mathrm{S} 1063784217080242$

[34] Щербаков И.П., Веттегрень В.И., Мамалимов Р.И., Махмудов Х.Ф. // ЖТФ. 2018. Т. 88. Вып. 7. С. 1009-1013. [Shcherbakov I.P., Vettegren V.I., Mamalimov R.I., Makhmudov Kh.F. // Tech. Phys. 2017. Vol. 88. N 7. P. 979-983.] DOI: http//dx.doi.org/10.1134/S1063784218070265

[35] Щербаков И.П., Веттегрень В.И., Мамалимов Р.И., Махмудов Х.Ф. // ЖТФ. 2019. Т. 89. Вып. 3. С. 388-391.

[36] Ребецкий Ю.Л., Сим Л.А., Маринин А.В. От зеркал скольжения к тектоническим напряжениям. Методы и алгоритмы. М.: ГЕОС, 2017. 234 с.

[37] Гиляров В.Л., Дамаскинская Е.Е., Кадомщев А.Г., Рассказов И.Ю. // Физико-технические проблемы разработки полезных ископаемых. 2014. № 3. С. 40-45.

[38] Гиляров В.Л. // ФТТ. 2011. Т. 53. Вып. 4. С. 707-710.

[39] Гиляров В.Л. // ФТТ. 2015. Т. 57. Вып. 11. С. 2204-2211.

[40] Адушкин В.В., Кочарян Г.Г., Новиков В.А. // Физика Земли. 2016. N 5. P. 13-24.

[41] Кочарян Г.Г. Геомеханика разломов. М.: Геос, 2016. 422 с.

[42] Мухамедиев Ш.А. // ДокЛ. РАН. 2015. Т. 461. С. 93-97.

[43] Мухамедиев Ш.А. // Физика Земли. 2019. № 3. С. 3-40.

[44] Соболев Г.А. // Физика Земли. 2019. № 1. С. 166-179.

[45] Ружич В.В., Кочарян Г.Г., Савельева В.Б., Травин А.В. // Геодинамика и тектонофизика. 2018. Т. 9. № 3 . C. 1039-1061. DOI: 10 .5800/GT-2018-9-3-0383

[46] Носов В.В. // Дефектоскопия. 2014. № 12. С. 24-35.

[47] Носов В.В., Бураков И.Н. // Дефектоскопия. 2004. № 2. C. 53-61.

[48] Макеев А.И., Чернышов Е.М. // Строительство и реконструкция. 2018. № 2 (76). С. 121-134.

[49] Фурса Т.В., Данн Д.Д., Петров М.В., Соколовский А.Н. // ЖТФ. 2019. Т. 89. Вып. 1. С. 99-106.
[50] Кочанов А.Н. Горный информационно-аналитический бюллетень (научно-технический журнал). 2018. № 1. C. 101-109.

[51] Томилин Н.Г., Махмудов Х.Ф. // Актуальные научные исследования в современном мире. 2017. № 10-4 (30). C. $145-152$.

[52] Савельев В.Н., Махмудов Х.Ф. // Евразийское научное объединение. 2018. Т. 1. № 12 (46). С. 25-28.

[53] Махмудов Х.Ф. // Евразийское научное объединение. 2018. T. 1. № 12 (46). C. $28-30$. 